\title{
Parkinson's Disease and Spinal Anaesthesia
}

\author{
Eylem Oğuz, İbrahim Öztürk, Derya Özkan, Jülide Ergil, Gözde Bumin Aydın \\ Clinic of Anaesthesiology and Reanimation, Dışkapı Yildırm Beyazıt Training and Research Hospital, Ankara, Turkey
}

Parkinson's is a neurodegenerative disease characterized by increased activity of GABA in basal ganglia and the loss of dopamine in nigrostriatum, associated with rigidity, resting tremor, gait with accelerating steps, and fixed inexpressive face. Being a neurological disease, spinal anaesthesia is often avoided in Parkinson's. Yet, in Parkinsons' patients, general anaesthesia may mask neurological symptoms in the intraoperative period and exacerbate them postoperatively. Moreover, the drugs administered in general anaesthesia more likely interact with anti-Parkinson drugs and may have side effects. With spinal anaesthesia, unlike general anaesthesia, because muscle relaxants and opioids are avoided, the exacerbation is not going to be masked due to muscle relaxation, and neurological symptoms may be distinguished clinically. In addition, the known effects of spinal anaesthesia, like suppression of surgical stress, postoperative pain relief, and early mobilization, may be advantageous in Parkinson's disease. Treated for Parkinson's disease for about 10 years at the age of 77 and with American Society of Anesthesiologists physical classification III (hyperlipidemia, hypertension, coronary artery disease, and chronic obstructive lung disease), a female patient was scheduled for elective surgery for fracture of the left distal tibia. In this case, we aimed to report a patient with Parkinson's disease who underwent spinal anaesthesia in order to avoid the disadvantages of general anaesthesia and reviewed the literature.

Key Words: Parkinson's disease, spinal anaesthesia, aged

\section{Introduction}

$\mathrm{P}$ arkinson's disease is a neurodegenerative disease characterized by neurotransmitter imbalance due to relative dopamine deficiency in caudate nucleus and putamen and loss of pigmented cells in substantia nigra (1). Current theories on its aetiology include mitochondria dysfunction and exposure to various toxins that leads to continuous activation of glutamate receptors $(1,2)$. Its clinical picture depends on increased gamma-aminobutyric acid activity due to dopamine deficiency. Consequently, characteristic symptoms such as resting tremor, rigidity in the extremities, bradykinesia, fixed facial expression, and gradually worsening gait disturbances are seen (2). In addition, orthostatic hypotension, dysphagia, diaphragmatic spasms, dementia and mental depression may also be seen (2). Maintenance of the balance between cholinergic and striatal dopaminergic activity forms the basis of medical treatment in Parkinson's disease, which can be treated either medically or surgically. Levodopa, selegiline, dopamine agonists (bromocriptine) and catechol O-methyltransferase (COMT) inhibitors are used for this purpose (1).

Among anaesthesia techniques, general anaesthesia is usually preferred in patients with Parkinson's disease. However, general anaesthesia may mask the symptoms of Parkinson or may trigger the symptoms in the postoperative period. Herein, therefore, we would like to present our spinal anaesthesia experience, which is rarely used in Parkinson's patients.

\section{Case Presentation}

A 77-year-old female patient was scheduled for elective surgery due to fracture in the distal left tibia; informed consent was obtained from the patient. Preoperative evaluation revealed that she has been receiving treatment for Parkinson's disease for 10 years. The patient with bilateral Parkinson's symptoms and mild gait disturbance on physical examination, was considered to have Stage III disease according to the 'Hoehn and Yahr' Parkinson's disease rating scale. As she had wheezing, consultation was requested from the pneumology department. She was diagnosed to have obstructive pulmonary disease based on respiratory function tests and treatment was commenced. Madopar (levodopa+benserazide), which she has been 
receiving for the treatment of Parkinson's disease, was continued at a dose of $125 \mathrm{mg}$ tablet $(3 \mathrm{x} 1)$. In addition, it was learned that she had hyperlipidaemia (for 15 years), hypertension (for 34 years) and coronary artery disease (for 15 years) and has been receiving Beloc-zok ${ }^{\oplus} 50 \mathrm{mg}$ tablet $(1 \mathrm{x} 1)$, Co-Diovan ${ }^{\oplus}$ 160/12.5 tablet (1x1), Ator $20 \mathrm{mg}$ tablet $(1 \times 1)$, Amlokard ${ }^{\oplus}$ $10 \mathrm{mg}$ tablet $(1 \mathrm{x} 1)$, Plavix ${ }^{\oplus} 75 \mathrm{mg}$ tablet $(1 \mathrm{x} 1)$ and Coraspin ${ }^{\circledR}$ $100 \mathrm{mg}$ tablet $(1 \mathrm{x} 1)$. Since the patient with American Society of Anesthesiologists (ASA) III disease, was scheduled for spinal anaesthesia, oral anticoagulant medications were discontinued for 7 days and daily subcutaneous enoxaparin at a dose of $0.4 \mathrm{~mL}$ was commenced $(1 \mathrm{x} 1)$. Blood analysis performed on the day before surgery revealed no coagulation defect or biochemical abnormality. The patient was admitted to the operating room and $1 \mathrm{mg}$ midazolam was administered via intravenous route for sedation after intravenous line was established. Thereafter, spinal anaesthesia was performed using $2.5 \mathrm{~mL}$ of $0.5 \%$ hyperbaric bupivacaine through $\mathrm{L}_{3-4}$ space using $25 \mathrm{G}$ needle after the patient was placed in decubitus position with assistance. Pinprick test, which was performed five minutes later, indicated that a T10 the level of anaesthesia was achieved. Her haemodynamic condition was stable during the surgery. Near the end of the surgery, dexketoprofen $50 \mathrm{mg}$ was administered as IV infusion. The patient was admitted to the recovery room without any problem at the end of the surgery that lasted for 2.5 hours, and then transferred to the ward without any complication.

\section{Discussion}

Spinal anaesthesia was planned for the patient presented herein as she had advanced stage chronic obstructive pulmonary disease. For this purpose, anticoagulant drugs that she has been receiving were discontinued seven days before the surgery and subcutaneous enoxaparin was commenced. Anti-Parkinson's treatment was continued up to and including the morning of surgery, since the half-life of levodopa is short and severe muscle rigidity might be encountered 6-12 hours after discontinuation of the drug (2).

Parkinson's disease involves many systems and therefore comprises various signs and symptoms. Neuromuscular system involvement forms a basis for prolonged immobilization and related increased risk of venous thromboembolism; gastrointestinal motility disorder and dysphagia forms a basis for aspiration, ileus and constipation; and obstructive or restrictive pulmonary disease and weakened respiratory muscles due to respiratory system involvement forms a basis for extubation difficulty, atelectasis and pneumonia (3). It has been demonstrated that patients with Parkinson's disease have a higher risk of aspiration pneumonia and urinary tract infections and bacterial infections as compared to those without Parkinson's disease (4). In the present case, we preferred spinal anaesthesia as it enables early mobilization and thereby reduces the risk of venous thromboembolism, as well as to eliminate the probability of difficulty in weaning from mechanical venti- lation due to muscle relaxation provided by neuromuscular blockers during general anaesthesia.

Besides the perioperative complications due to clinical organ involvement, we aimed to avoid drug interactions and likely adverse effects of drugs that are frequently used in anaesthesia practice. As Parkinson's patients are prone to developing cardiac arrhythmias, the use of arrhythmogenic inhalation anaesthetics such as halothane should be avoided in these patients (5). Even though it has been stated that modern inhalation anaesthetics would probably be safer (6), the fact that sevoflurane might cause electrocardiographic alterations that could progress to malignant arrhythmia is an important point (7). Among intravenous anaesthetics, the effect of ketamine leading to sympathetic nervous system response that results in tachycardia and hypertension is an effect that should be taken into account particularly in patients with cardiac disease (2). Concurrent cardiac disease in Parkinson's patients makes the use of ketamine and sevoflurane debatable. Preferring propofol because of its rapid metabolism necessitates patient-based decision as it causes dyskinesia in Parkinson's patients (8). On the other hand, the fact that opioids, which are powerful analgesics, lead to acute dystonic reactions and muscle rigidity restricts its usage in Parkinson's patients (2). Therefore, we performed spinal anaesthesia only with local anaesthetics because of probability of passing into systemic circulation. Moreover, we used a non-opioid analgesic (dexketoprofen $50 \mathrm{mg}$ IV) for postoperative analgesia.

Spinal anaesthesia is generally not preferred in patients with neurological diseases. The possibility of exacerbation of disease symptoms is the basic concern. In the literature, the use of spinal anaesthesia in Parkinson's patients is very rare (9, 10). Therefore, there is no definitive data whether spinal anaesthesia poses an absolute or a relative contraindication. On the other hand, the possibility of multiple drug use during general anaesthesia and disease-specific complications make spinal anaesthesia, particularly at the levels (below T4) that would not cause cardiac adverse effects (hypotension, bradycardia), more convenient in some selected patients.

\section{Conclusion}

We are in the opinion that spinal anaesthesia does not pose an absolute or a relative contraindication and can be safely and effectively used in Parkinson's patients.

Informed Consent: Written informed consent was obtained from the patient who participated in this case.

Peer-review: Externally peer-reviewed.

Author Contributions: Concept - E.O., İ.Ö.; Design - İ.Ö., D.Ö., J.E., G.B.A.; Supervision - E.O., İ.Ö., D.Ö., J.E.; Data Collection and/or Processing - E.O., İ.Ö., G.B.A.; Analysis and/or Interpretation - E.O., İ.Ö., D.Ö., J.E., G.B.A.; Lit- 
erature Review - E.O., İ.Ö., G.B.A.; Writer - E.O., İ.Ö., G.B.A.; Critical Review - D.Ö., J.E.

Conflict of Interest: No conflict of interest was declared by the authors.

Financial Disclosure: The authors declared that this study has received no financial support.

\section{References}

1. Kelton T, Mc Clung H, Scarfo K, Hecker JG, Neurologic Diseases. In: Fleisher LA (Ed). Anesthesia and Uncomman Diseases $5^{\text {th }}$ edition. Philadelphia: W. B. Saunders Company, 2005.pp.261-301.

2. Dierdorf SF, Walton S. Anesthesia for patients with rare and coexisting diseas. In: Barash PG, Cullen BF, Stoelting RK (Eds). Clinic Anesthesia, Fifth Edition. Philadelphia: Lippincott Williams Wilkins 2006.pp.502-28.

3. Patel SG, Stickrath CR, Anderson M, Klepitskaya O. How should Parkinson's disease be managed perioperatively? The web site: http://www.the-Hospitalist.org/details/article/704937/ (23.09.2013)

4. Pepper PV, Goldstein MK. Postoperative complications in Parkinson's disease. J Am Geriatr Soc 1999; 47: 967-72.

5. Nicholson G, Pereira AC, Hall GM. Parkinson's disease and anaesthesia. Br J Anaesth 2002; 89: 904-16. [CrossRef]

6. Rudra A, Rudra P, Chatterjee S, Das T, Ray M, Kumar P. Parkinson's Disease and Anaesthesia. Indian J Anaesth 2007; 51: 382-8.

7. Kleinsasser A, Kuenszberg E, Loeckinger A, Keller C, Hoermann C, Lindner KH, et al. Sevoflurane, but not propofol, significantly prolongs the Q-T interval. Anesth Analg 2000; 90: 25-7. [CrossRef]

8. Krauss JK, Akeyson EW, Giam P, Jankovic J. Propofol-induced dyskinesias in Parkinson's disease. Anesth Analg 1996; 83: 420-2. [CrossRef]

9. Alkaya F, Kurdemir P, Atay T. Regional anesthesia for parkinson Disease: Case report. Turkish Journal of Geriatrics 2012; 15: 473-5.

10. Shipton EA, Roelofse JA. Anaesthesia in a patient with Parkinson's disease. A case report. S Afr Med J 1984; 65: 304-5. 